\title{
When to suspect inherited platelet disorders and how to diagnose them
}

\author{
Eun Sil Park, MD \\ Department of Pediatrics, Institute of Health Science, Gyeongsang National University College of Medicine, Jinju, Korea
}

Inherited platelet disorders (IPDs) are a heterogeneous group of mucocutaneous bleeding disorders of variable severity caused by genetic defects. The relevant genes encode an array of molecules of diverse function, reflecting megakaryopoiesis, platelet formation, and platelet function. Many IPD genes are widely transcribed across blood cell types and other tissues. Hence, patients with IPDs frequently present with pathologies reaching well outside the blood system. ${ }^{1)}$

Accurately diagnosing IPDs is important for the appropriate clinical management of individual patients and enables a reliable estimate of their real prevalence. Glanzmann thrombasthenia (GT) and Bernard-Soulier syndrome (BSS) often present with severe bleeding symptoms early in life and are easily recognized by the platelet aggregation defect pattern. ${ }^{2,3)}$ Some IPDs present with syndromic features such as hearing loss, renal impairment or cataracts (MYH9-related disorders), heart, face, or bone dysmorphisms (thrombocytopenia absent radii, amegakaryocytic thrombocytopenia with radioulnar synostosis), ocular involvement, mental retardation, eczema, infection, and small platelets (Wiskott-Aldrich syndrome), reduced or delayed skin pigmentation (Hermansky-Pudlak syndrome) can help in its recognition and diagnosis, ${ }^{4}$ but making the diagnosis remains quite challenging in the majority of cases.

Current guidelines favor a tiered approach to diagnosing IPD. ${ }^{3,5)}$ The initial evaluation must include a careful history of family and consanguinity. IPDs should be suspected when patients have the following characteristics: (1) bleeding not proportional to platelet count; (2) family history of thrombocytopenia, myelodysplasia, or leukemia; (3) family history of undefined mucocutaneous bleeding disorder regardless of the platelet count; and (4) whenever von Willebrand disease is being considered as the cause of bleeding. ${ }^{4)}$ If clear abnormalities emerge from the clinical assessment and/or bleeding score, ${ }^{6}$ ) the proband should then be subjected to preliminary laboratory investigations, including full blood count, prothrombin time, activated partial thromboplastin time, and von Willebrand factor (VWF) screening tests (VWF antigen, ristocetin cofactor activity, and factor VIII coagulant activity). If these results are normal, a diagnostic work-up for IPD should be pursued. Given that several IPDs are associated with thrombocytopenia, a mildly reduced platelet count should not exclude further IPD testing.

The Scientific and Standardization Committee International Society on Thrombosis and Haemastasis suggested the diagnostic algorithm flowchart ${ }^{3}$.

GT, the most frequently encountered IPD, features lifelong sustained mucocutaneous bleeding. Hemorrhagic diathesis is notable for its variability and the lack of correlation between the biochemical platelet abnormalities and clinical severity. Platelets fail to aggregate in response to stimuli because they have reduced or absent functional aIlb3 integrin (formerly known as GPIIbIIIa). ${ }^{2,3)}$ BSS is a rare autosomal recessive bleeding disorder characterized by defects of the GPIb-IX-V complex, a platelet receptor for VWF and moderate thrombocytopenia and giant platelets on a peripheral blood smear. ${ }^{2,3)}$

$\mathrm{Shim}^{7)}$ described that genetic abnormalities of IPDs identified in recent studies by genome-wide association study and nextgeneration sequencing and genetically confirmed Korean IPD patients. The recent Korean Pediatric Hematology-Oncology Group (K-PHOG) study using targeted exome sequencing in multiple Korean centers was also presented. Considering the elaborate diagnostic steps for IPDs and the differences in available diagnostic techniques by institutions, the application of highthroughput sequencing will simplify the diagnostic process and reduce delays.

Establishing a conclusive molecular diagnosis is the bedrock of good hematologic practice because it informs optimal treatment and can provide clarity about disease progression. For IPDs, this is particularly important in severe cases and those associated with early-onset clinical pathologies such as myelofibrosis, lung fibrosis, renal insufficiency, and malignancy. ${ }^{8}$ Thrombocytopenias caused by variants in RUNX1, ETV6, and ANKRD26 are associated with increased risk of myeloid malignancy, whereas for Wiskott-Aldrich syndrome and amegakaryocytic thrombocy. topenia caused by MPL variants, treatment by allogeneic hematopoietic stem cell transplantation or gene therapy may require consideration. ${ }^{9}{ }^{10)}$ Moreover, genetic counseling can be provided

Corresponding author: Eun Sil Park, MD. Department of Pediatrics, Gyeongsang National University College of Medicine, 15 Jinju-daero 816 beon-gil, Jinju 52727, Korea 凶E-mail: gespark@gsnu.ac.kr, https://orcid.org/0000-0001-9344-7191

Received: 3 October, 2019, Revised: 13 December, 2019, Accepted: 31 December, 2019

This is an open-access article distributed under the terms of the Creative Commons Attribution Non-Commercial License (http://creativecommons.org/licenses/bync/4.0/) which permits unrestricted non-commercial use, distribution, and reproduction in any medium, provided the original work is properly cited.

Copyright (c) 2020 by The Korean Pediatric Society 
if the diagnosis is confirmed at the DNA level.

We just started a nationwide K-PHOG survey of IPDs with next generation-sequencing. Due to clinical diversity as well as genetic heterogeneity, pediatricians must pay more attention to their diagnosis. In the genomic era, it is hoped that genetic panels for IPDs will be available soon and covered by medical insurance.

\section{Conflicts of interest}

No potential conflict of interest relevant to this article was reported.

See the article "Genetic classification and confirmation of inherited platelet disorders: current status in Korea" in Volume 63 on page 79 .

\section{References}

1. Westbury SK, Turro E, Greene D, Lentaigne C, Kelly AM, Bariana TK, et al. Human phenotype ontology annotation and cluster analysis to unravel genetic defects in 707 cases with unexplained bleeding and platelet disorders. Genome Med 2015;7:36.
2. Israels SJ, El-Ekiaby M, Quiroga T, Mezzano D. Inherited disorders of platelet function and challenges to diagnosis of mucocutaneous bleeding. Haemophilia 2010;16(Suppl 5):152-9.

3. Gresele P; Subcommittee on Platelet Physiology of the International Society on Thrombosis and Hemostasis. Diagnosis of inherited platelet function disorders: guidance from the SSC of the ISTH. J Thromb Haemost 2015;13:314-22.

4. Lambert MP. What to do when you suspect an inherited platelet disorder. Hematology Am Soc Hematol Educ Program 2011:377-83.

5. Lentaigne C, Freson K, Laffan MA, Turro E, Ouwehand WH; BRIDGEBPD Consortium and the ThromboGenomics Consortium. Inherited platelet disorders: toward DNA-based diagnosis. Blood 2016;127:281423.

6. Elbatarny M, Mollah S, Grabell J, Bae S, Deforest M, Tuttle A, et al. Normal range of bleeding scores for the ISTH-BAT: adult and pediatric data from the merging project. Haemophilia 2014;20:831-5.

7. Shim YJ. Genetic classification and confirmation of inherited platelet disorders: current status in Korea. Clin Exp Pediatr 2020;63:79-87.

8. Zhang MY, Churpek JE, Keel SB, Walsh T, Lee MK, Loeb KR, et al. Germline ETV6 mutations in familial thrombocytopenia and hematologic malignancy. Nat Genet 2015;47:180-5.

9. Hacein-Bey Abina S, Gaspar HB, Blondeau J, Caccavelli L, Charrier $\mathrm{S}$, Buckland $\mathrm{K}$, et al. Outcomes following gene therapy in patients with severe Wiskott-Aldrich syndrome. JAMA 2015;313:1550-63.

10. Ballmaier M, Germeshausen M. Congenital amegakaryocytic thrombocytopenia: clinical presentation, diagnosis, and treatment. Semin Thromb Hemost 2011;37:673-81. 